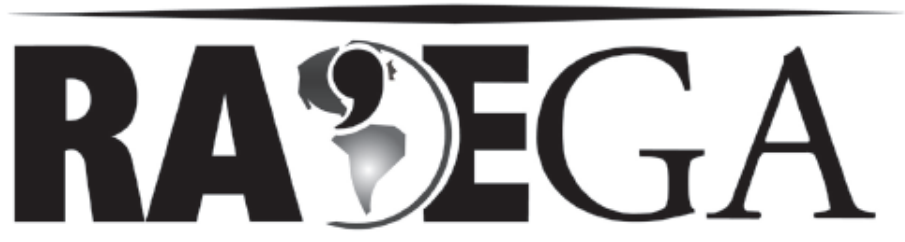

O ESPAÇO GEOGRÁFICO EM ANÁLISE

\title{
A REPRESENTAÇÃO DO ESPAÇO DO SAGRADO EM ESTADOS DE ÊXTASE NO PENSAMENTO MÍSTICO INDIANO
}

THE REPRESENTATION OF SACRED SPACE IN ECSTASY STATES IN THE INDIAN MYSTIC THINKING

\author{
Vladimir Luis de Oliveira ${ }^{1}$
}

\section{RESUMO}

O objetivo deste artigo aponta para a necessidade em se ampliar a discussão do espaço do sagrado para além da percepção material dos templos e dos lugares santos. Experiências extático-religiosas que comumente se apresentam na tradição indiana, conhecidas como samadhi ou moksha, interferem no campo sensorial dos místicos ou devotos e na forma de representação do mundo que é descrita pelos textos sagrados das escolas filosóficas da Índia. Esta discussão procura evidenciar a necessidade de um paradigma que considere a existência do espaço como uma construção social relativa, considerando-se os mitos e as experiências transpessoais durante o processo do numinoso.

\footnotetext{
${ }^{1}$ Doutor pelo Programa de Pós-Graduação em História da Universidade Federal do Paraná - UFPR, PósDoutorado no Programa de Pós-Graduação na Geografia pela Universidade Federal do Paraná - UFPR, Curitiba, Paraná, Brasil. vladimiroliveira@msn.com
} 
Palavras-chave: espaço do sagrado; misticismo hindu; êxtase religioso.

\section{ABSTRACT}

The objective of this article is to show the need of enlarging the discussion about sacred space to an instance beyond the material perception of temples and sacred places. Ecstasy-religious experiences, common in Indian tradition, which are known as samadhi or moksha, have the power of interfering in the mystics or devotees's sensitive domain, and in the formal representation of the world described in the Indian sacred books. This discussion seeks to stress out the need of a paradigm which accepts the existence of space as a relative social construction, taking into consideration the myths and transpersonal experiences during the numinous process.

Keywords: sacred space, Hindu mysticism, religious ecstasy.

\section{INTRODUÇÃO}

Uma das questões centrais na Geografia da religião está na apropriação do campo conceitual do espaço do sagrado em sua dimensão mítica enquanto experiência individual ou coletiva. Não se trata, neste caso, de qualquer percepção espacial do sagrado como comumente é apresentado em estudos da religião, cuja tônica reflexiva está mais atrelada à dimensão material dos templos ou de lugares santos ou sagrados.

Trata-se mais particularmente de se aperceber e se apropriar de uma realidade mais específica, ainda que mais difusa em termos conceituais: o espaço do sagrado como fruto da psyché. A sua organização transcendental a partir dos conceitos e experiências humanas fundamentais do sagrado: a análise da cartografia dos elementos simbólicos do sagrado numa construção da experiência em si. As práticas ascéticas conduzem indivíduos a experiências transpessoais, modificando sobremaneira a forma ordinária em se compreender o espaço. É um mundo da experiência direta com os arquétipos construídos pela cultura do devoto em que este passa a se constituir parte deste cosmos.

O objetivo deste artigo não está em negar as ideologias espaciais como uma representação mítica do espaço. Nem tampouco contrapô-las à representação profana espacial do sagrado, conforme aponta Claval na análise 
do espaço do sagrado (CLAVAL, 1985, p.263). Mas também é improvável compreender profundamente a relação entre mito e o espaço do sagrado sem chegar aos limites da a-espacialidade com o advento do numinoso. A questão é muito mais complexa do que previra Haesbaert (2009), ao fazer uma exaustiva crítica à base conceitual de desterritorialização, identificando-a mais como um mito discursivo da pós-modernidade.

A desterritorialização, em termos do sagrado, representa a possibilidade do indivíduo em eliminar as fronteiras entre o "eu" e o mundo. Os registros das experiências da indiferenciação entre o homem e o espaço remontam à prémodernidade. Há como evidências desta afirmação, os afrescos do homem no paleolítico que representavam um campo de experiências religiosas de integração, pois os ritos reproduzidos reafirmavam a unidade do homem com o tempo atmosférico, com a paisagem, com os animais e com seus semelhantes. Bateson (2006, p.370) denominou este fenômeno como uma experiência de integração.

Uma perspectiva semelhante aparece em Yu-Fu Tuan ao dizer que "os espaços do homem refletem a qualidade de seus sentidos e sua mentalidade. A mente frequentemente extrapola além da evidência sensorial." (TUAN, 1983, p.18).

Tomando por base esta reflexão entre o numinoso e o espaço do sagrado nos sistemas místico-filosóficos da Índia, procura-se argumentar neste artigo que em estados de samadhi ou de profunda transe religiosa, altera-se o campo sensorial a tal ponto, que não há distinção entre o homem o espaço, ou, há uma vivência desterritorializada ou deslocada do espaço. $O$ aprofundamento do numinoso também altera as representações simbólicas do espaço mítico, pois as imagens ou a linguagem não encontram categorias explicativas suficientemente elaboradas para descrever o fenômeno psíquico em sua totalidade. A separação tradicional entre sujeito e objeto, consoante à lógica cartesiana, matriz da ciência moderna e da racionalidade instrumental, é substituída por uma reintegração arquetípica do indivíduo com o self através do samadhi ou moksha. 


\section{O ESPAÇO DO SAGRADO EM ESTADOS ALTERADOS DE CONSCIÊNCIA NA CULTURA SAGRADA INDIANA}

O misticismo hindu menciona três tipos distintos de espaço: o que representa o universo físico denominado de mahakasha; o mental denominado chittakasha, responsável pelos sonhos, pensamentos e imagens. O terceiro e último, é o que representa o sagrado por excelência. É denominado shiddakasha ou espaço do conhecimento e pertence à esfera das experiências espirituais genuínas (BHASKHARANANDA, 2005, p.31).

O filósofo Cassirer identifica no espaço mítico a representação da consciência religiosa, e que ocupa uma posição intermediária entre o espaço sensível da percepção (ou empírico) e entre o espaço do conhecimento puro ou geométrico. O espaço mítico caracteriza-se, em sua essência, por uma identidade originária cuja narrativa está intimamente associada a uma cosmografia e cosmogonia específica. O mito parte de uma correspondência físico-espacial entre o homem que nele habita para então elaborar a narrativa mítica da sua unidade de origem (CASSIRER, 2004, p.151-164). O pensamento mítico orienta e organiza o mundo de acordo com determinados pontos de vista espaciais que são muito distintos do pensamento empírico ao realizar a organização espacial do cosmos (CASSIRER, 2001, p.47).

O fato é que a apropriação do espaço mítico do sagrado é particularmente reelaborada pelo místico, cuja percepção estaria mais para uma apercepção para além do contínuo espaço-tempo. A visão cartesiana que serviu como modelo para o homem racional é confrontada e questionada hoje com novas racionalidades e até trans-racionalidades que, ainda que não consigam descrever totalmente a experiência mística, consideram-na como uma experiência legítima da experiência humana.

Para a compreensão desta experiência, as filosofias místicas indianas elaboraram-se diversos discursos controversos, representados em diferentes escolas ou dárshanas: Samkhya, Vedanta, Mimansa, Yoga, Nyaya, Vaisheshika, entre outras (MULLER, 1899). Cada uma delas procura enfatizar a partir de suas representações místicas, a essência do sagrado enquanto 
verdade religiosa: melhor caminho para se atingir a transcendência em vida e, desta forma, experimentar a realização da psique no espaço-tempo do sagrado. Um universo sensorial em que conceitos desfazem-se totalmente de seus sentidos.

Por isso, é necessário reposicionar a interpretação e a vivência espacial dos mitos segundo a máxima saussuriana que sustenta que o signo linguístico não está direcionado para a realidade, mas para a própria linguagem. Seguindo este princípio, o real e o concreto só fazem sentido em um sistema semiológico, como a língua, quando revestido de valores que determinam o seu sentido (SAUSSURE, 2006, p.128). Isto levou Foucault a concluir que a linguagem enquanto significação torna-se independente da realidade (FOUCAULT, 2000, p.416; MACHADO, 2005, p.144). A matriz deste pensamento está no pressuposto de que realidade e discurso não se apóiam na relação palavra-coisa, mas no signo-idéia (MARQUES, 2008, p.56).

Em Cassirer observa-se uma análise semelhante ao tomar por objeto a expressão linguística. A linguagem enquanto forma simbólica está muito distante de ser apenas uma cópia do mundo dos sentidos ou da intuição, porque possui intrinsecamente um caráter independente que consiste em atribuir sentido a si mesmo (CASSIRER, 2001, p.65). Estas interpretações pautadas pela semiologia, ainda que promovam um avanço na compreensão do fenômeno religioso, são limitadas para a análise do mito na perspectiva fenomenológica.

Para Barthes, a saída para entender o mito para além da língua, estaria em interpretá-lo enquanto uma estrutura metalinguística em que, o significante (imagem acústica) teria uma dimensão muito maior do que o significado (base conceitual). O mito teria uma massa ilimitada de representações. O que se estabelece no mito é um signo (totalidade associativa entre o conceito e imagem) de base muito mais complexa (BARTHES, 2007, p.204-205). O mito seria, enfim, uma fala definida pela sua intenção que se encontra petrificada, purificada e eternizada. O mito elimina a base histórica das coisas e naturaliza a imagem do real. Contudo, os homens não estabelecem relações de verdade, mas sim de utilização com o mito, pois é um valor: ao modificar o sistema que o 
rodeia, pode-se determinar com exatidão o seu alcance. Objetos míticos podem até serem abandonados por um tempo, mas ao serem restituídos aos seus lugares de origem, e restabelecida a sua natureza de linguagem-objeto, pode-se promover a desocupação do real para que o mito assuma seu lugar (BARTHES, 2007, p.215-237).

No entanto, ainda que se possa aceitar a compreensão do mito enquanto uma estrutura metalingüística, é preciso relativizar a premissa de que o mito cumpre seu papel através da desistorização e desocupação do real. Em última instância, pode-se até ganhar uma relativa compreensão e significação do mundo da vida. A função do mito, segundo Bateson (2006, p.343; 1988, p.160), não é de reprodução empírica da história, mas recriar uma narrativa poética da sacralidade na vida dos homens. As estruturas poéticas exercem profundamente o poder comunicativo através de metáforas.

Enfim, ao analisar particularmente a dimensão empírica do êxtase religioso enquanto uma verdade fenomênica, conclui-se que somente através da linguagem que se constrói o sentido do universo conceitual do sagrado, mas, com certeza, a experiência do numinoso está para além da função simbólica da linguagem, enquanto elemento constituinte do real.

O papel do mito está em restituir a base singular do pensamento simbólico, que é uma parte substancial do ser humano e que é anterior à razão discursiva e à linguagem. Nas palavras de Eliade "as imagens, os símbolos e os mitos não são criações irresponsáveis da psique; elas respondem a uma necessidade e preenchem a uma função: revelar as mais secretas modalidades do ser." (ELIADE, 2001, p.8-9).

Por isso, o mito não deve ser visto como "ficção", pois ele tem "vida", na medida em que ele proporciona modelos de conduta aos homens e estabelece valor e significação a vida humana. O mito representa a narrativa da história sagrada em seu tempo primordial, em que tudo começou (ELIADE, 1991, p.5).

A representação dos espaços do sagrado em estados modificados de consciência pode levar ao entendimento de que o mundo fenomênico não representa a negação do mundo espiritual, mas uma de suas possíveis representações, ainda que imperfeita. Por isso, qualquer lugar pode ser 
assento para a experiência do samadhi: debaixo de uma árvore, tal como é descrita a história sagrada de Gautama Buda, num templo, numa montanha como espaço vivencial de Ramana Ramarshi ou mesmo numa prisão, como foi o caso de Aurobindo. Ainda que os mais diferentes espaços possam servir de palco para a conexão com o self, é somente pela persistência individual do yogue ou do místico que se atinge estados mentais de integração e em estados modificados de consciência.

O estado de samadhi conduz a uma profunda metamorfose da percepção e da psique. Usando categorias jungianas podemos afirmar que este estado é um mergulho profundo no inconsciente individual, permitindo uma conexão imediata do self com os arquétipos sagrados do inconsciente coletivo. O numinoso ou a experiência do sagrado é potencialmente uma experiência de êxtase, ao estimular a vivência de um estado não-ordinário de consciência. Este fenômeno conduz invariavelmente o sujeito a eclipsar diferentes percepções espaciais: o da consciência individual e o espaço do inconsciente coletivo.

Jung (2008, p.37-133) sustentava que tudo que é tocado pelo arquétipo de anima, torna-se numinoso. É o arquétipo da dimensão feminina da alma que representa a soma de todas as afirmações do inconsciente coletivo; é a entrada ao mundo dos deuses e das representações religiosas. O arquétipo é a forma da manifestação do inconsciente coletivo e está intimamente vinculado à construção dos mitos e, estes nada mais são do que a essência da alma. Com a conexão do anima através do yoga alcança-se o estado da graça.

O numinoso é a manifestação da experiência religiosa e que não possui um caráter racional. Este fenômeno exerce um duplo movimento sobre a psique: o de repressão e geração de um sentimento de temor, como também de felicidade e de excelso, podendo conduzir o indivíduo em certas condições ao êxtase sexual (OTTO, 2007, p.83-89). Através da contemplação meditativa, a psique pode experimentar visões e sensações que ultrapassam a realidade empírica, e que não podem ser apreendidas pelo caminho da cognição teórica como é feito pela ciência, pois são experiências reais e diretas da intuição (OTTO, 2007, p.183). 
Esta experiência do sagrado promove uma ruptura contínua na percepção espaço-temporal dualista de base cartesiana, pois o sagrado é uma experiência que restitui o sentido de totalidade (BATESON, 1994). A fragmentação entre espaço transcendente e imanente, ou entre deuses e almas individuais é transcendida. O monismo como experiência imediata é vivida pelo místico que prefere se conduzir pelo silêncio e pelo êxtase, transcendendo inclusive à necessidade de discussões filosóficas místicas.

Quando os devotos buscam os lugares sagrados, não buscam apenas a identificação do espaço material do sagrado. Em sua subjetividade procuram vivenciar a mesma experiência que seus líderes espirituais ou gurus relataram durante o êxtase místico. É muito mais retorno a um tempo e a um espaço primordial. Jung (1980, p.31) preferia identificá-la como uma experiência do vazio ao descrever a prática da contemplação interior do Yoga.

Ainda que os mitos de origem influenciem as arquiteturas dos templos, chegando em alguns casos, aos limites das cidades, estas representariam apenas a dimensão material da espiritualidade. No caso hindu, por exemplo, templos podem ser erigidos reproduzindo a estrutura dos corpos dos deuses, dos pés (Gopuram - que é a entrada), até ao núcleo do templo que representa a cabeça (Garbhagrham) (GIL FILHO, 2009, p.101-104).

Cassirer expressou a opinião de que espiritualidade e realidade empírica podem até imbricarem-se, sem que o primeiro permaneça aprisionado ao factual. Pois, o que se "vê no real nunca é o real mesmo em sua imediatez, mas o sentido transcendente que nele encontra sua apresentação mediata (CASSIRER, 2004, p.426).

O Advaita-Vedanta é filosofia mística de princípio monista com uma concepção holística do mundo espiritual que é marcada pela não diferenciação entre a alma individual e Brahman, enquanto a força universal que organiza e dá sentido ao mundo. Estes princípios interferem diretamente na forma como o observador passa a entender a experiência religiosa e a construção arquetípica do espaço do sagrado.

Dentre os aspectos mais significativos do mito hindu influenciado pelo Advaita-Vedanta está o princípio da indiferenciação entre a alma individual e a 
transcendência. O Atman ou Paratman é puro, é consciência indiferenciada auto-iluminada, intemporal e a-espacial, impensável e não diferenciável de Brahman que subjaz e apóia a pessoa humana individual. Atman é um estado da consciência humana em que a diferenciação entre sujeito e o objeto é transcendido (DEUTCSH, 1973, p.48).

Quanto ao espaço, a consciência centrada no Atman é a-espacial, porque o fenômeno espacial estabelece relações entre objetos em determinada ordem empírica. E esta não pode ser aplicada ao fenômeno espiritual porque isto limita a própria experiência espiritual em si (DEUTSCH, 1973, p.48). espaço ou território do sagrado, no limite, é experiência ilusória de Maya, não representando, enfim, a verdadeira essência da experiência espiritual.

Contudo, a divisão entre realidade do sagrado e a realidade dos sentidos, nas filosofias místicas indianas, possui uma classificação muito mais complexa envolvendo diversas categorias e, também, significativas divergências de opinião quanto ao entendimento do mundo sensível e ao mundo transcendente.

O Advaita-Vedanta, segundo Sankhara - principal filósofo desta doutrina - haveria no mundo duas formas manifestas de realidade: uma de ordem prática e fenomênica, chamada de vyâvahârika e, outra que se refere ao numinoso e ao absoluto, denominado pâramârtthika. Estas realidades são responsáveis pela produção de dois tipos distintos de conhecimento: o conhecimento incorreto (mithyagnana), que é associado ao universo dos fenômenos e, o perfeito conhecimento (samyagjnana) que representa a realidade absoluta (GRISWOLD,1900, p.73).

Para o pensamento ocidental, o mundo sensível é considerado o mundo da produção da ciência, mas para o Vedanta representa o mundo da ignorância, ainda que a transcendência possa ser seu objeto de conhecimento. A realidade última, concebida antropomorfologicamente, é identificada a um baixo Brahman e, a última realidade concebida desantropomorfologicamente corresponde à imagem do Alto Brahman. O baixo Brahman refere-se a um conhecimento inferior chamado de aparâ vidyã. Identifica Brahman a um conceito supremo da religião ou como projeção da imaginação religiosa. $\mathrm{O}$ alto 
Brahman está associado a um conhecimento mais elevado - parâ vidyâ - e nele Brahman aparece como um supremo conceito da filosofia e da razão. $\mathrm{Na}$ cosmologia de Sankhara, quando Brahman - segundo as Upanishads aparece como mortal, fenomênico, condicionado ao tempo e ao espaço, nomeadamente, como ordenador do mundo da experiência, este sistema é denominado de Maya. Mas, nem mesmo Maya, escaparia das antinomias interpretativas: não é um ser, muito menos um não-ser, mas um tornar-se. Não é nem idêntico ao puro Brahman e não é o oposto a ele, como também não é absolutamente irreal, uma vez que é real para a consciência (GRISWOLD, 1900, p.73-78).

No sistema filosófico Samkhya, cuja estrutura é de base dualista, apresenta-se divergências significativas das outras filosofias místicas indianas de base monista, tal como o filosofia Vedanta. As diferenças fundamentais estão em torno da distinção ou indiferenciação do mundo material e espiritual e, entre a separação ou não da alma individual e do Espírito Universal. No entanto, a visão da espacialidade enquanto um fenômeno do sagrado, não apresenta diferenças nítidas entre as filosofias místicas. Este princípio é comumente aceito pelas estruturas discursivas destas escolas concorrentes que consideram que o objetivo máximo do homem, é viver plenamente 0 sagrado para poder alcançar o samadhi, experiência em que o espaço fenomênico é destituído do campo da percepção.

Diversos filósofos modernos recuperam esta máxima da relativização do espaço e aplicam-na na estrutura teórica de suas reflexões. A visão mítica do mundo reproduz uma percepção do espaço que em si não é espacial, afirmou categoricamente Cassirer (2004, p.155). Schopenhauer (2005, p.60) encantouse com o pensamento místico indiano ao expressar a metáfora de que o mundo fenomênico [o que também se aplica ao espaço] é manifestação do poder ilusório de Maya, ou ainda, de estado de sonho. Através destas metáforas, Schopenhauer identifica convergências filosóficas entre o pensamento indiano e o ocidental, que remonta desde o pensamento clássico grego.

Platão sustentava que as pessoas viviam apenas em sonho, e que somente os filósofos se emprenhavam em acordar. Píndaro dizia que o homem 
era o sonho de uma sombra. Sófocles repetia "vejo que nós viventes, nada somos senão figuras ilusórias, imagens das sombras fugidas". Shakespeare sustentava que "somos feitos do mesmo estofo que os sonhos, e a nossa breve vida está rodeada de um sono" (SCHOPENHAUER, 2005, p.60).

A metáfora é uma ferramenta que permite compreender os fenômenos religiosos através de analogias e como as culturas humanas ressignificam e reelaboram os diferentes sentidos, incluindo-se, neste caso, a do espaço do sagrado. Bateson (1988, p.109-149), aponta as metáforas como comparações destituídas de explicações. Elas mantém inalteradas as relações que ilustram, apenas substituem as palavras por coisas ou pessoas.

Ainda, mesmo no campo ontológico da dimensão do sagrado, há distinções a serem consideradas. A constituição espacial do sagrado enquanto samadhi ou moksha é distinta da experiência do espaço do sagrado enquanto experiências mágicas tradicionais do sagrado conhecidas como siddhis.

O siddhi ou mago obtém plenos poderes através de uma possessão mística, obtida através de tapas (austeridades ascéticas) em que o indivíduo conquista poderes milagrosos. Segundo esta mitologia do sagrado, ele pode alçar vôos xamânicos como um pássaro, atingindo distâncias incríveis. No Rig Veda, diz-se que o siddhi "num piscar de olhos ele vai do mar oriental ao mar setentrional". Há aqui a apresentação de conquistas de espaços ou territórios mitológicos do sagrado para além do tempo. De certa forma, pode-se aludir ao princípio de que os siddhis foram aprisionados pelos poderes de Maya (ELIADE, 2002, p.443).

O moksha ou samadhi é uma experiência mística de plena consciência para além do racional ou de integração mental. O misticismo na cultura indiana representa uma conexão espiritual direta com a intuição. Torna-se possível alcançar uma compreensão imediata do sentido da vida de uma forma muito mais real do que é obtida pela mera razão (DASGUPTA, 1959, p.IX). Bateson dizia que a experiência do sagrado era muito maior do que a percepção do plano consciencial, pois, a consciência é limitada, fragmentária e esboça uma visão limitada da realidade. É uma experiência mais profunda, no plano da mente ecológica, em que se estabelece a conexão entre todas as formas de 
vida e com o planeta em termos holísticos. Não há, enfim, separação entre espécies, ou entre pleroma (mundo material inanimado) e criatura. O que de distinto é que a criatura usa a informação do ambiente: compara, interage e se integra ao mesmo, diferentemente do pleroma, que mantém uma relação passiva com o mundo através das leis físicas e químicas. Tudo está sistemicamente integrado formando um elo, compondo entre si em um sistema mental complexo. Não há, porém, um propósito consciente por qualquer das partes suscetível a réplicas, como em uma interação entre pessoas. O universo mental se constitui muito mais como um universo auto-organizado (BATESON, 2006, p.229; BATESON, p.23-35, 1994).

Os poderes miraculosos dos siddhis poderiam se converter em obstáculos para este intento, pois dificultariam suplantar a força do ego. Nas palavras de Patanjali é dito "tesamadav upasarga vyuttane siddhaya", isto é, os poderes dos siddhis podem se converter em obstáculos ou distrações para 0 desenvolvimento do perfeito samadhi (PATANJALI, 2007, p.94). Seriam, enfim, um misticismo de ordem inferior (DASGUPTA, 1959, p. VIII). O samadhi é muito mais uma viagem ao espaço interior da alma que, lentamente se desfaz em seu caminho para a ascese e para o desapego da dimensão egóica. É uma experiência direta e imediata com Brahman ou Purusha. No livro Gherandha Samhita (um dos mais importantes do Hatha Yoga e que foi escrito provavelmente no séc. XVII, por um autor desconhecido, um discípulo da tradição vaishinava), nos versos 12 e 13 exprimem a seguinte premissa: yogin deve realizar o yoni mudra, unindo-se a Shakti, perceber que o Paramatman é o Purusha e que ambos unem-se em um só. Mediante isso o yogin entra em êxtase e chega a compreender o Aham Brahaman (eu sou Brahman). Isto conduz a advaita samadhi (TINOCO, 2007, p.100).

Nas tradições do Yoga influenciadas pelo Vedanta, há uma descrição de uma modalidade de meditação profunda que conduz a uma determinada manifestação de samadhi que é conhecida como Nirvichara Samadhi. Nesta técnica, o meditante concentra-se nos tanmatras (ou elementos densos da realidade) e procura eliminar a consciência do espaço-tempo (BHASKARANANDA, 2005, p.148). 
Para Cassirer (2001, p.73-74) quanto mais rico é o conteúdo das formas simbólicas, mais se definha o seu conteúdo essencial. É somente através da suspensão das determinações das imagens dos mitos ou da arte, das palavras da linguagem ou dos símbolos intelectuais do conhecimento e através retorno ao "puro nada" dos místicos, é que o homem pode reconduzir-se à verdadeira fonte primordial do ser.

\section{CONCLUSÃO}

Na verdade, podemos afirmar que a experiência fenomênica ao universo da consciência ordinária territorializa, ao passo que a experiência do sagrado em samadhi, desterritorializa toda a percepção e a representação simbólica face ao mundo sensível.

Contudo, o foco desta reflexão é demonstrar como esta leitura da experiência do sagrado é representada em diferentes formas pelas filosofias místicas. Estas filosofias apontam que as experiências extáticas, conhecidas como samadhi ou moksha, alteram não somente a percepção do tempo como também a percepção do espaço. O espaço-tempo da consciência é outro e, portanto, os modelos teóricos de base cartesiana usados pelos saberes da geografia não dão conta da explicar o fenômeno religioso, porque ainda tendem a fortalecer a compreensão do sagrado como um construto empírico e sensorial, externo ao sujeito que vive a experiência do numinoso.

O foco é mais especifico: analisar o quadro da percepção do espaço do sagrado face ao aprofundamento das experiências religiosas. Os mitos, os ritos, as ideologias espaciais do sagrado estão presentes, mas deixam de ser significativamente importantes.

Hoje, podemos dizer que o fenômeno religioso do samadhi ou moksha não se circunscreve mais ao território da Índia ou adjacências. Em face da globalização, percebe-se que Ocidente está cada vez mais aberto a experiências religiosas distintas. $E$ isto não significa necessariamente uma reprodução ortodoxa das religiosidades tradicionais da Índia. Na maior parte estas religiosidades são reelaboradas e adaptadas às culturas ocidentais, 
fazendo delas uma prática sincrética em que a divisão entre Ocidente e Oriente fica cada vez mais difícil de definir. Até porque estados modificados de consciência estão presentes em diversas religiões: desde as chamadas "religiões primitivas" até as macro-religiões ocidentais.

O sagrado permite a integração do homem ao ecossistema que o rodeia. Restitui-Ihe a sua natureza sistêmica, que é imperceptível através da consciência de base racional. Daí a necessidade dos sonhos e dos transes para que o homem se integre com a mente ecológica do planeta. Os mitos, os rituais, as invocações da morte, a arte, a poesia, a música, as práticas respiratórias, as práticas meditativas e as plantas e substâncias psicodélicas de tradição mágico-religiosa, facilitam este processo mental sistemicamente (KENNY, 1999).

\section{REFERÊNCIAS BIBLIOGRÁFICAS}

BARTHES, R. Mitologias. Rio de Janeiro: EDIFEL, 2007.

BATESON, G. Pasos hacia una ecología de la mente: una aproximación revolucionaria de la compreensión del hombre.Buenos Aires: Lohlé-Lumen, 1988.

. Una unidad sagrada: pasos ulteriores hacia una ecologia de la mente. Barcelona-ES: Edisa Editorial, 2006.

; BATESON, M. C. El temor de los angeles. Barcelona: Gedisa, 1994.

BHASKARANANDA, S. Meditação: a mente e a Yoga de Patanjali. Rio de Janeiro: Lótus do Saber, 2005.

CASSIRER, E. A filosofia das formas simbólicas: a linguagem. São Paulo: Martins Fontes, 2001.

A filosofia das formas simbólicas: o pensamento mítico. São Paulo: Martins Fontes, 2004.

CLAVAL, P. Les Ideólogies spatiales. In: Cahiers de géographie du Québec. vol. 29, n 77, 1985, p. 261-269. Disponível em: http://www.erudit.org Acesso em: 10.02.2012

DASGUPTA, S. N., Hindu mysticism. New York: Frederick Ungar Publishing, 1959.

DEUTSCH, E. Advaita Vedanta. Honolulu: University of Hawaii Press, 1973.

ELIADE, M. Mito y realidad. Editorial Labor: Barcelona, 1991.

Imagens e símbolos: ensaios sobre o simbolismo mágico-religioso.

São Paulo: Martins Fontes, 2001. 
O xamanismo e as técnicas arcaicas do êxtase. São Paulo: Martins Fontes, 2002.

GIL FILHO, S. F. Paisagem religiosa. In: Junqueira, Sérgio (org.). O sagrado: fundamentos e conteúdos do ensino religioso. Curitiba: IBPEX, 2009.

FOUCAULT, M. As palavras e as coisas. São Paulo: Martins Fontes, 2000.

GRISWOLD, H. D. Brahman: a study in the History of the Indian Philosophy. New York: Macmillan Company, 1900.

HAESBAERT, R. O mito da desterritorialização: do fim dos territórios à multiterritorialidade. Rio de Janeiro: Bertrand Brasil, 2009.

JUNG, C. G. Os arquétipos e o inconsciente coletivo. Petrópolis: Vozes, 2008.

Psicologia e religião oriental. Petrópolis: Vozes, 1980.

KENNY, V. A Noção do Sagrado em Gregory Bateson: o que ela nos pode dizer sobre uma vida construtiva? Out/1999 Disponível em: <http://www.palasathena.org> Acesso em: 11/02/2012.

MACHADO, R. Foucault: a filosofia e a literatura. Rio de Janeiro: Jorge Zahar, 2005.

MARQUES, L. M. B. Análise discursiva da metáfora: revisitando o estruturalismo saussuriano. 2008: UFES, Dissertação (Mestrado em Linguistica), Programa de Pós-Graduação em Estudos Linguísticos Universidade Federal do Espírito Santo, Vitória.

MULLER, M. The six system of Indian Philosophy. London and Bombay: Longsman Green, 1899.

OTTO, R. O sagrado: os aspectos racionais da noção do divino e sua relação com o racional. Petrópolis: Vozes, 2007.

PATANJALI. Yoga sutra. Chapada dos Veadeiros-GO: Paraiso dos Pantavas, 2007. Tradução e comentários de Gustavo Dauster e Howard Resnick.

SAUSSURE, F. de. Curso de lingüística geral. São Paulo: Cultrix, 2006.

SCHOPENHAUER, A. O mundo como vontade e como representação. São Paulo: UNESP, 2005.

TINOCO, C. A. Gheranda Samhita. Conhecimento Editorial: Curitiba, 2007.

TUAN, Y.-F. Espaço e lugar: a perspectiva d experiência. São Paulo: DIFEL, 1983. 